Research article

\title{
Regional scale investigation of net primary productivity associated to dominant land cover classes of Indian Himalayan region
}

\author{
Sandeep Soni*, Sandipan Mukherjee and Kireet Kumar \\ Watershed Processes and Management Group, G.B. Pant Institute of Himalayan Environment and Development, \\ Kosi-Katarmal, Almora, 263643, Uttarakhand, India
}

*Corresponding Author: sandeepsoni80@gmail.com

[Accepted: 26 June 2017]

\begin{abstract}
This study is an attempt to understand regional variability of net primary productivity (NPP) of four major land cover classes (LCC), namely evergreen broadleaf forest (EBL), mixed forest (MF), grassland (GL) and crop land (CL), over the Indian Himalayan Region (IHR) including Nepal and Bhutan. The study period is chosen to be the 11 years of 2001-2011. Therefore, the spatial distribution along with inter-annual and total NPP is analysed using Moderate Resolution Imaging Spectroradiometer (MODIS) LCC and NPP products having a spatial resolution of 0.1 degree. MODIS NPP is based on algorithm developed by applying the radiation conversion efficiency logic to the prediction of daily Gross Primary Productivity (GPP), fractional absorbed photosynthetically active radiation, photosynthetically active radiation and other surface meteorological fields. Irrespective of the spatial distribution, the monthly maximum NPP for EBL, MF, GL and CL were found to be 6.4, 6.3, 4.5 and $4.6 \mathrm{gC} . \mathrm{m}^{-2}$. day $^{-1}$, respectively. The annual total NPP for EBL, GL and CL over the entire IHR were found to be decreasing with the rate of $370.3,185.1$ and $822.5 \mathrm{gC} . \mathrm{m}^{-2}$.day ${ }^{-1}$ whereas, the annual total NPP value for the MF category was found to have a small rate of annual enhancement of $16.0 \mathrm{gC}^{-2} \mathrm{~m}^{-2}$.day ${ }^{-1}$. Overall for the period of 2001-2011, the annual reduction in the NPP values of all the four major LCC was found to be $1.3 \mathrm{KgC} . \mathrm{m}^{-2}$.day ${ }^{-1}$ indicating a significant carbon loss in terms of biomass of IHR.
\end{abstract}

Keywords: Net Primary Productivity - Land Cover Changes - MODIS - Himalayan Region.

[Cite as: Soni S, Mukherjee S \& Kumar K (2017) Regional scale investigation of net primary productivity associated to dominant land cover classes of Indian Himalayan region. Tropical Plant Research 4(2): 264-273]

\section{INTRODUCTION}

Net primary productivity (NPP) is an important component in biosphere functioning and carbon balancing at regional and global scale as it provides a measure of the amount of $\mathrm{CO}_{2}$ removed from the atmosphere through photosynthesis and respiration (Liu et al. 1999). NPP is also an essential step in providing means of evaluating spatial patterns in productivity as well as inter-annual variation and long-term trends in biosphere behaviour. NPP represents the net carbon input from the atmosphere to the terrestrial vegetation (Melillo et al. 1993) and is one of the important biophysical variables presenting vegetation activities. Therefore, NPP is one of the most important components of the biogeochemical carbon cycle (Tan et al. 2007). However, studies on the impact analysis and spatiotemporal dynamics of NPP are a new research topic and have attracted much attention recently. Such research activities are spurred by global issues, such as global change, indirect sustainable management and conservation of biodiversity (Jinguo et al. 2006). Since NPP is the fundamental ecological variable, not only because it measures the $\mathrm{CO}_{2}$ assimilation, but it also indicates type of the land surface area (e.g., crops, forests) and status of a wide range of ecological processes (Roy et al. 2001), continuous monitoring of NPP, would therefore, be important to gather useful information for estimation of amount of $\mathrm{CO}_{2}$ removed from the atmosphere by biosphere (Bonan 2008, Grosso et al. 2008), to understand the management of natural resources (Liu et al. 1997) and the global carbon cycle.

The Himalayan region is a hotspot of natural biodiversity and is extremely vulnerable to intensive anthropogenic activities and natural calamities. This highly fragile region having rugged terrain and unique topography is sensitive to regional and global-scale changes in climate (Palni et al. 1998). Furthermore, 
changing landscape pattern, changing ecology and forest degradation are amongst the major environmental issues of Himalaya (Singh et al. 1984, Ives \& Messerli 1990). Due to the heterogeneity and complexity of Himalayan ecosystems, a better understanding of the relationship between climate change and net primary productivity distribution is important to predict future carbon dynamics (Zhang et al. 2012). Although, information regarding the changes in land cover classes (LCC) (Soni 2017) and NPP for the few selected regions of Indian subcontinent (Kumar et al. 2011) are available for large scale analyses for the entire country (Ramakrishnan 1988, Chhabra \& Dadhwal 2004, Singh et al. 2011, Bala et al. 2013) and for some Himalayan states of India (Agrawal \& Goyal 1987, Sharma et al. 1998, Dhaulakhandi et al. 2010, Joshi \& Pant 2012, Shrestha et al. 2012), no detailed regional scale Himalaya specific analyses of changes in NPP associated with changes in LCC are available. Therefore, this study aims at exploring the temporal variation of regional scale NPP values over the Himalayan region using significant LCC. Within this overarching aim, particular objectives of this study include: (i) identification of trends of spatial changes in the major LCC, (ii) investigation of mean month wise NPP value for significant LCC (iii) variability estimation of annual sum of NPP over the Himalayan region for selected LCC and (vi) assessment of correlation between major LCC specific annual NPP and precipitation.

\section{METHODOLOGY}

Study area and data used

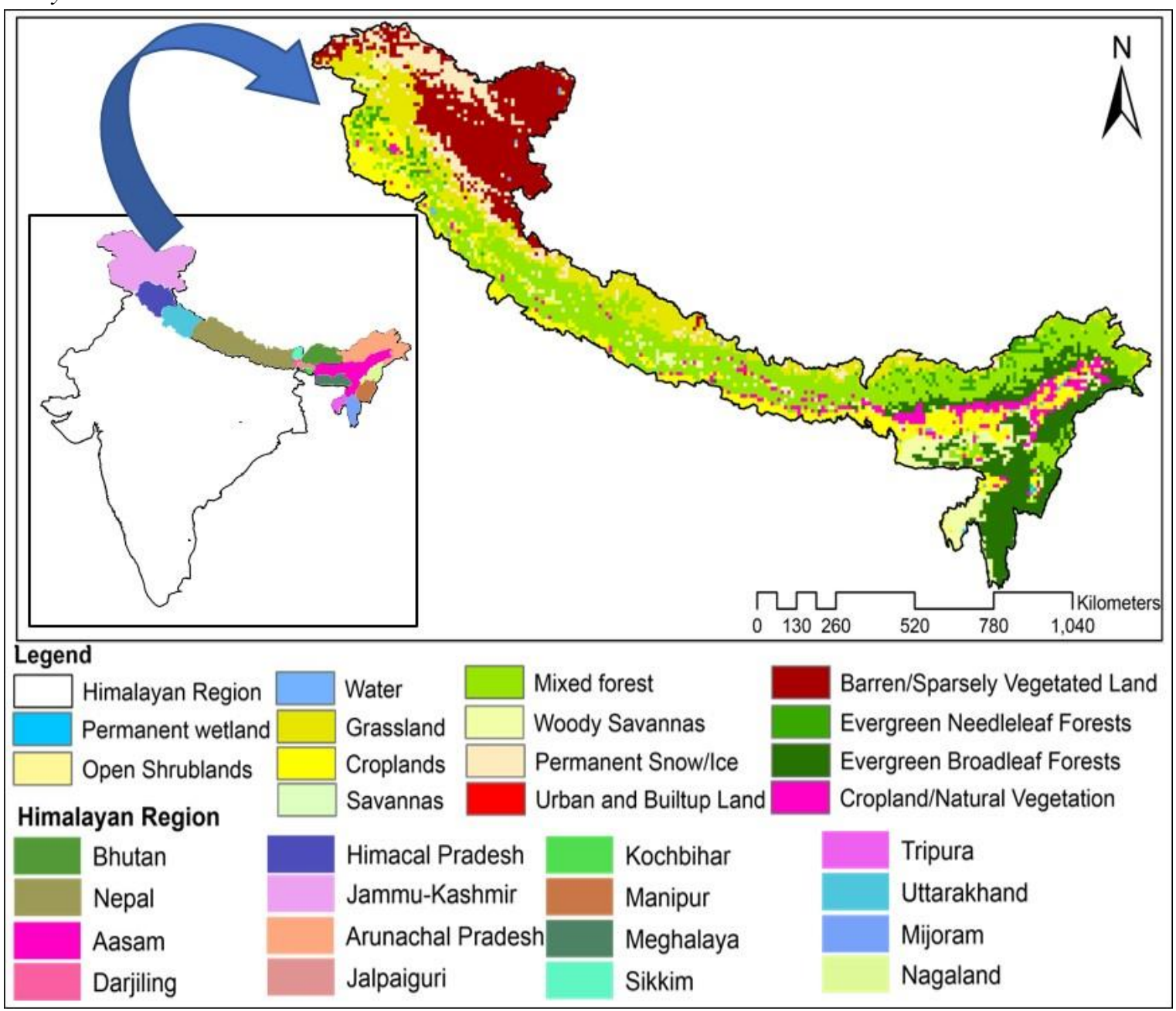

Figure 1. Location map of the study area.

In order to address the above objectives, regional scale land cover data from MODIS (Moderate Resolution Imaging Spectroradiometer, www.neo.sci.gsfc.nasa.gov, spatial resolution 0.1 degree) were used for the Indian Himalayan region (IHR) that include Nepal and Bhutan Himalaya for the period 2001 to 2011. The study area is extended from $21^{\circ} 56^{\prime} 30^{\prime \prime} \mathrm{N}$ to $37^{\circ} 5^{\prime} 30^{\prime \prime} \mathrm{N}$ latitude and $72^{\circ} 31^{\prime} 50^{\prime \prime} \mathrm{E}$ to $97^{\circ} 24^{\prime} 50^{\prime \prime} \mathrm{E}$ longitude (Fig. 1). The entire domain has approximate size of $9.16 \mathrm{lac} \mathrm{Km}^{2}$. There were 17 different land cover classes for the entire 
domain. However, we have restricted our analyses for four major classes namely, evergreen broadleaf forest (EBL, accounts for $12.2 \%$ of the total land cover), mixed forest (MF, accounts for $24.8 \%$ of the total land cover), grass land (GL, accounts for $13.7 \%$ of the total land cover) and cropping land (CL, accounts for $11.1 \%$ of the total land cover) which altogether accounts for $61.8 \%$ of the total area of the IHR (Table 1). However, the four major LCC do not include barren or sparsely vegetated land cover as, presumable, they are responsible for minute variation in the NPP values. Algorithm for the global scale production of annual land cover supplied by MODIS can be found in Strahler (1999). In short, the MODIS land cover data were produced by compositing eight different land cover parameters from different MODIS channels with inputs from Earth Observatory Satellite on monthly basis. The final land cover data from MODIS were then validated with several ground observations for data improvement.

Table 1. Land cover classes and area of land cover classes for the Indian Himalayan region.

\begin{tabular}{llll}
\hline S/N & Land cover classes & $\begin{array}{l}\text { Average area } \\
\text { covered }\left(\mathbf{k m}^{2}\right)\end{array}$ & $\begin{array}{l}\text { \% of the total area } \\
\text { of IHR }\end{array}$ \\
\hline 1 & Water & 3120.6 & 0.3 \\
2 & Evergreen Needleleaf Forests & 14345.7 & 1.6 \\
3 & Evergreen Broadleaf Forests & 112060.6 & 12.2 \\
4 & Deciduous Needleleaf Forests & 0.0 & 0.0 \\
5 & Deciduous Broadleaf Forests & 0.0 & 0.0 \\
6 & Mixed Forests & 227488.7 & 24.8 \\
7 & Closed Shrublands & 67.4 & 0.0 \\
8 & Open Shrublands & 4153.3 & 0.5 \\
9 & Woody Savannas & 66250.8 & 7.2 \\
10 & Savannas & 78.6 & 0.0 \\
11 & Grasslands & 125205.2 & 13.7 \\
12 & Permanent Wetlands & 639.8 & 0.1 \\
13 & Croplands & 101856.9 & 11.1 \\
14 & Urban and Built-Up Lands & 696.0 & 0.1 \\
15 & Cropland/Natural Vegetation & 46202.7 & 5.0 \\
16 & Permanent Snow/Ice & 56788.0 & 6.2 \\
17 & Barren/Sparsely Vegetated Land & 156994.8 & 17.1 \\
\hline
\end{tabular}

The NPP values for the four dominant LCC of our study were obtained from the MODIS monthly global data set of NPP (www.neo.sci.gsfc.nasa.gov) for the time period of 2001 to 2011 having a spatial resolution of 0.1 degree. Details of the algorithm used to derive the MODIS NPP values can be found in Running et al. (1999). However, a brief description of the algorithm is provided here. The fundamental notion of linear relationship between the absorbed photosynthetically active radiation (APAR) and the NPP (Monteith 1972, 1977) of a well-watered crop plant was used to produce this data. Although, such simplistic algorithm is insufficient to derive NPP values for the entire earth as many other meteorological and biological factors can modulate NPP of a plant (see Running et al. 1999 for detail). Therefore, the present data were developed by applying the radiation conversion efficiency logic to the predictions of daily Gross Primary Productivity (GPP), using satellite-derived fractional absorbed photosynthetically active radiation (FPAR) and independent estimates of photosynthetically active radiation (PAR) and other surface meteorological fields. Subsequently, the NPP values were computed by subtracting the maintenance and growth respiration terms from GPP. The maintenance respiration and growth respiration components were derived from allometric relationships linking daily biomass and annual growth of plant tissues to satellite-derived estimates of leaf area index. To address fourth objective, TRMM (Tropical Rainfall Measuring Mission) precipitation data having spatial resolution of 0.25 degree (see TRMM 2011 for detail) was downloaded from the website http://disc.gsfc.nasa.gov/datacollection/TRMM_3 B43_V7.shtml for above mentioned time period and further analysed with ArcGIS software.

In order to address the first objective of this study, at first, the annual global land cover values were extracted for the Himalayan region over the period 2001 to 2011 using the ArcGIS version 10.0 software. Next, the four dominant LCC (EBL, MF, GL and CL) were identified and number of pixels within the study domain for individual LCC was counted. The spatial resolution of remote sensing data was 0.1 degree. Therefore, total area covered by individual LCC for each year of study was computed. Finally, trend of LCC-wise spatial distribution was computed using simple linear regression. To address the second and third objective of this study, using the similar method of LCC extraction, NPP values were extracted for each LCC. Then, arithmetic 
mean of NPP values of each month was estimated and their spatial distributions were studied. The average monthly maxima of NPP $\left(\overline{N P P_{\max }^{m}}\right)$ over the 11 years period was computed following:

$$
\overline{N P P_{\max }^{m}}=\frac{1}{Y} \sum_{M y=1}^{M y=11} N P P_{\max }^{m}
$$

Where, $N P P_{\max }^{m}=$ maximum NPP value of each month for 2001 to 2011 over the entire domain, $Y=$ number of years and $M y=$ summation of months (e.g. Jan. to Jan.) for 2001 to 2011.

Similarly, the average total NPP value for a particular month and summed over the 11 years of data period $\left(\overline{N P P_{t o t}^{m}}\right)$ was computed following:

$$
\overline{N P P_{t o t}^{m}}=\frac{1}{Y} \sum_{M y=1}^{M y=11} N P P_{t o t}^{m}
$$

Where $N P P_{t o t}^{m}=$ total NPP value of each month for 2001 to $2011, Y=$ number of years.

Finally, total annual sum of NPP for a single year $\left(N P P_{t o t}^{A n n}\right)$ for the four dominant classes were estimated following:

$$
N P P_{\text {tot }}^{\text {Ann }}=\sum_{\text {Jan } Y}^{D e c Y} N P P_{t o t}
$$

Where, $N P P_{t o t}=$ total NPP value of each year, $Y=$ year (2001 to 2011).

\section{RESULTS AND DISCUSSION}

The four major LCC for this study are EBL (Class 1), MF (Class 2), GL (Class 3) and CL (Class 4). The annual land cover distribution of these classes for the entire IHR over the period of 2001-2011 shown in figure 2. A quick look on the LCC throughout 2001-2011 reveals that the maximum forest (EBL and MF) distribution of the IHR is concentrated in the eastern Himalaya. When the spatial distribution of each of this classes were analysed for the entire Himalayan region, it was found that the distribution of EBL was restricted within the eastern Himalayan region with exception of the Brahmaputra river valley area, which was mostly dominated by croplands, presumably rice paddies. The westernmost significant distribution of EBL was observed near the border of the state of West Bengal of India and Nepal. The MF was found to be ubiquitously distributed over the eastern and central Himalayan region, whereas over the north-western IHR, distribution of MF was found to be sparse. As expected Most of the CL areas were observed near the lower altitudes and, GLs were observed in the higher altitudes. Two significant concentrations of GL were observed in the upper region of the Indian state of Kashmir and over the high altitudes of Central Nepal.

In order to estimate the rates of changing area distribution of the selected LCC, trend lines were produced for an area of each LCC using linear regression method (Fig. 3). It was observed that except for MF, land cover areas of all the other three classes were decreasing. The rate of land cover area enhancement of MF was found to be $177.2 \mathrm{Km}^{2}$.year ${ }^{-1}\left(\mathrm{r}^{2}=0.13\right)$ for the study period. Although, rates of land cover area decrement for the EBL, CL and GL were found to be $43.5\left(r^{2}=0.03\right), 30.9\left(r^{2}=0.03\right)$ and $81.0 \mathrm{Km}^{2}$. year $^{-1}\left(\mathrm{r}^{2}=0.22\right)$. Reduction of the EBL forests of the eastern Himalayan region can be attributed to the decreasing trend of rainfall and moisture availability of the region for which a significant proportion of the EBL forest type is replaced by MF category (Chakraborty 2009, Reddy et al. 2013). Similarly, reduction of high altitude GL of IHR can be attributed to overgrazing and decrement of rainfall resulting replacement of GL by barren and sparsely vegetated land (Pandit et al. 2007, Farooq \& Rashid 2010, Reddy et al. 2013).

In order to investigate the average month-wise variation in the NPP values of selected classes, first we have explored the spatial variation. It is obvious that the spatial distribution of NPP (Fig. 4) of a LCC would only correspond to the spatial distribution of that particular LCC, however, the month-wise maximum and minimum of NPP would be different. To start with the spatial distribution of monthly averages of NPP of EBL, it was observed that the maxima of NPP (>5 gC. $\left.\mathrm{m}^{-2} \cdot \mathrm{day}^{-1}\right)$ for EBL forests were mostly concentrated over the Manipur, Mizoram states of the north-east Himalayan region. Similarly, the maxima of NPP for MF (> $5 \mathrm{gC} . \mathrm{m}^{-}$ ${ }^{2} \cdot$ day $^{-1}$ ) were mostly observed for those forests situated in the foothills of Himalaya. The maxima of NPP for GL $\left(>3 \mathrm{gC} \cdot \mathrm{m}^{-2} \cdot \mathrm{day}^{-1}\right)$ were mostly observed for those regions which were adjacent to the MF category. 
Soni et al. (2017) 4(2): 264-273

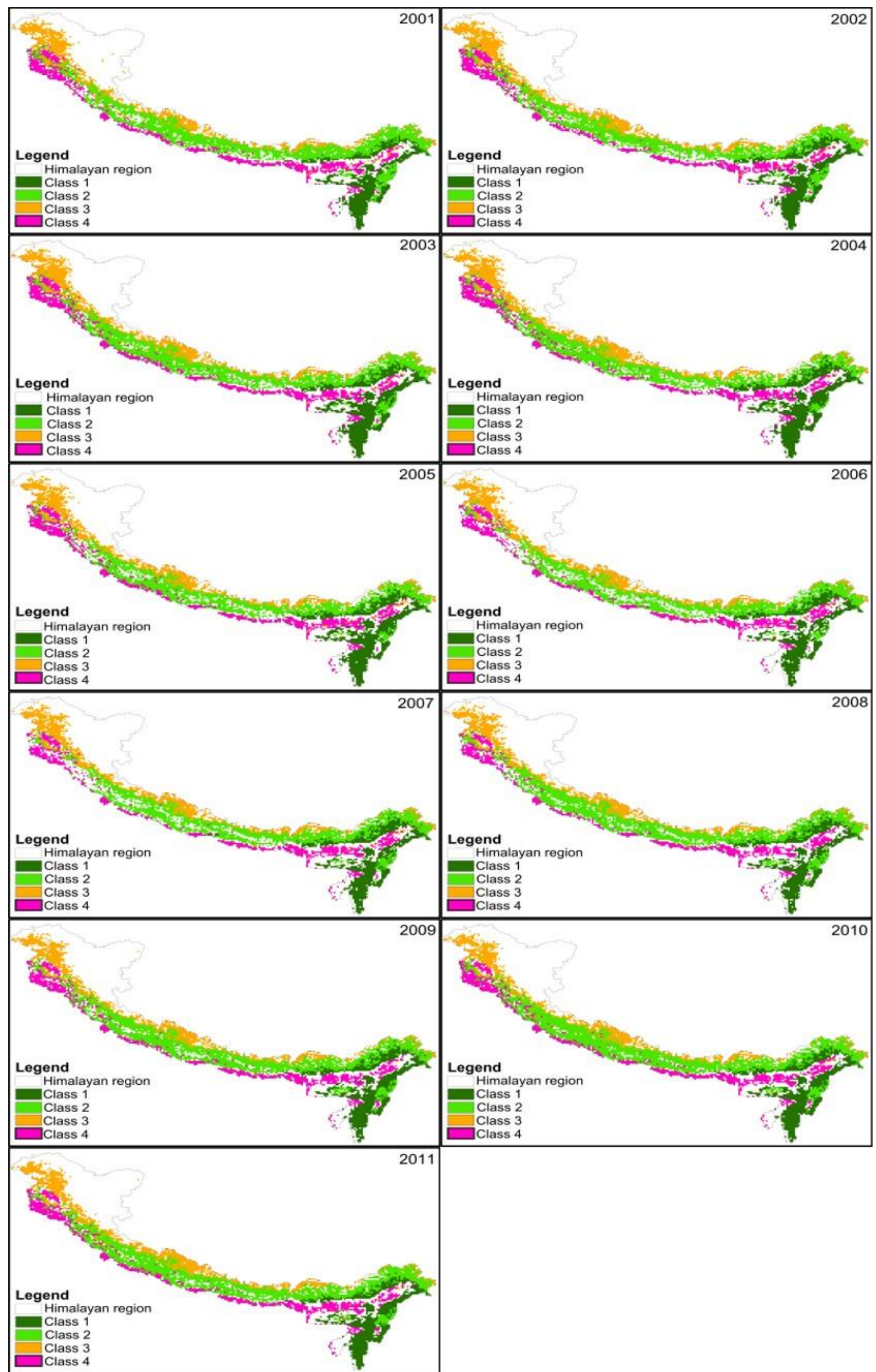

Figure 2. Annual land cover distribution for the period 2001-2011: Class 1- Evergreen broadleaf forest (EBL); Class 2Mixed forest (MF); Class 3- Grass land (GL); Class 4- crop land (CL). 


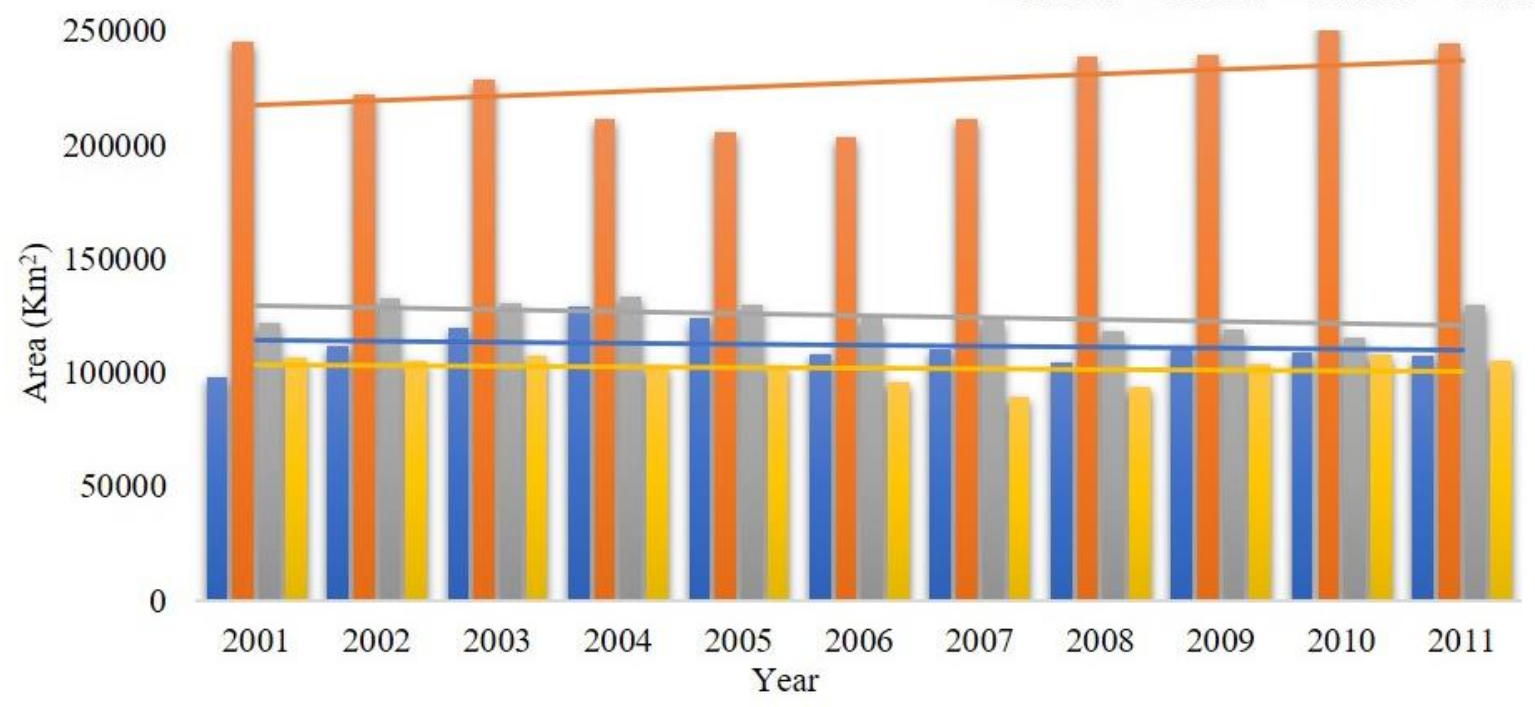

Figure 3. Trends in the changing area distribution of selected LCC. The horizontal lines are produced using linear regression method. [Class 1- Evergreen broadleaf forest (EBL); Class 2- Mixed forest (MF); Class 3- Grass land (GL); Class 4- crop land $(\mathrm{CL})]$

The variation in the monthly maximum NPP values, estimated following equation (1), of each class for 11 years (2001-2011) is represented in figure (5A). The $\overline{N P P_{\max }^{m}}$ values for EBL, MF, GL and CL were found to be 6.4, 6.3, 4.5 and $4.6 \mathrm{gC} . \mathrm{m}^{-2}$.day ${ }^{-1}$, respectively. The $\overline{N P P_{\max }^{m}}$ for EBL and MF were observed for the month of April and May, whereas the same for GL and CL were observed for the month of June and July. The peak values of GL and CL for June-July can be attributed the highest growth of the respective vegetation due to monsoon rainfall. The NPP values for both EBL and MF category were found to have two maxima on April and October, whereas the GL was found to have a single peak. This variation in the NPP values can be easily attributed to the peak of leaf initiation and leaf senescence.

When the month-wise average of total NPP were investigate for our selected LCC (following equation (2)), variations were found to be mostly matching the trend of $\overline{N P P_{\max }^{m}}$ values, except for the MF category, for which the highest value of $\overline{N P P_{\text {tot }}^{m}}$ were observed for the month of October (5895.8 gC.m ${ }^{-2}$.day $\left.{ }^{-1}\right)$ (Fig. 5B).

Finally, when the total NPP values of each year for the selected classes were estimated following equation (3), a significant reduction was observed for the MF category during 2004 and 2005 (Pandit et al. 2007, Chakraborty 2009, Farooq \& Rashid 2010, FSI 1999-2011). However, no such significant reduction in other LCC were observed for that period. The overall trend in the NPP tot $A n n$ values for the EBL, GL and CL were found to be decreasing with the rate of $307.3\left(\mathrm{r}^{2}=0.1\right), 185.1\left(\mathrm{r}^{2}=0.5\right)$ and $822.5\left(\mathrm{r}^{2}=0.7\right) \mathrm{gC} \cdot \mathrm{m}^{-2} \cdot \mathrm{day}^{-1}$. Although, $N P P_{t o t}^{A n n}$ values for the MF category was found to have a small rate of annual enhancement during 2001-2011, $16.0\left(\mathrm{r}^{2}=0.0\right) \mathrm{gC} \cdot \mathrm{m}^{-2}$.day ${ }^{-1}$ (Fig. 6). The annual reduction in the NPP values of all the four major LCC was found to be $1.3 \mathrm{KgC} \cdot \mathrm{m}^{-2} \cdot \mathrm{day}^{-1}\left(\mathrm{r}^{2}=0.24\right)$.

To justify above mentioned reduction in trend of major LCC and NPP ${ }_{t o t}^{A n n}$, trend was assessed between four major LCC specific annual NPP and precipitation (Fig. 7). It was observed that precipitation was decreasing with a rate of $6 \mathrm{~mm} \cdot \mathrm{hr}^{-1}\left(\mathrm{r}^{2}=0.01\right)$. However, precipitation was correlated with NPP values of all the four major LCC to identify significant values. The observed value $\left(\mathrm{r}^{2}\right)$ for $N P P_{t o t}^{A n n}$ of EBL was -0.5 (p-value $=<0.001$ ), MF was 0.2 (p-value $=<0.04)$, GL was 0.8 (p-value $=<0.001)$ and CL was 0.3 (p-value $=<0.001)($ Fig. 8).

The detailed analysis has yielded a few surprising results about LCC and NPP. In corroboration to the results published in Reddy et al. 2013. It was found that LCC and NPP of EBL were decreasing over the Himalayan region in the last decade (Gupta et al. 2006), while LCC and NPP of MF showed increasing trend over the study area. However, such a significant decreasing trend was also observed for the remaining two classes i.e. GL and $\mathrm{CL}$ and, the total area covered by these last two classes were comparatively smaller than EBL and MF. In the case of GL, the primary productivity during December to February remains minimal due to very low temperature in the Alpine region where grasslands are mostly found. Similarly, pre-monsoon months of April to May remain non-productive for CL due to dry summer. Although, the variation in NPP associated to CL for the summer months was found to be area specific as the Brahmaputra river basin area in the North-eastern region 
showed a high variation in productivity whereas the same for the lower part of Central and Western Himalayan region showed little variation.

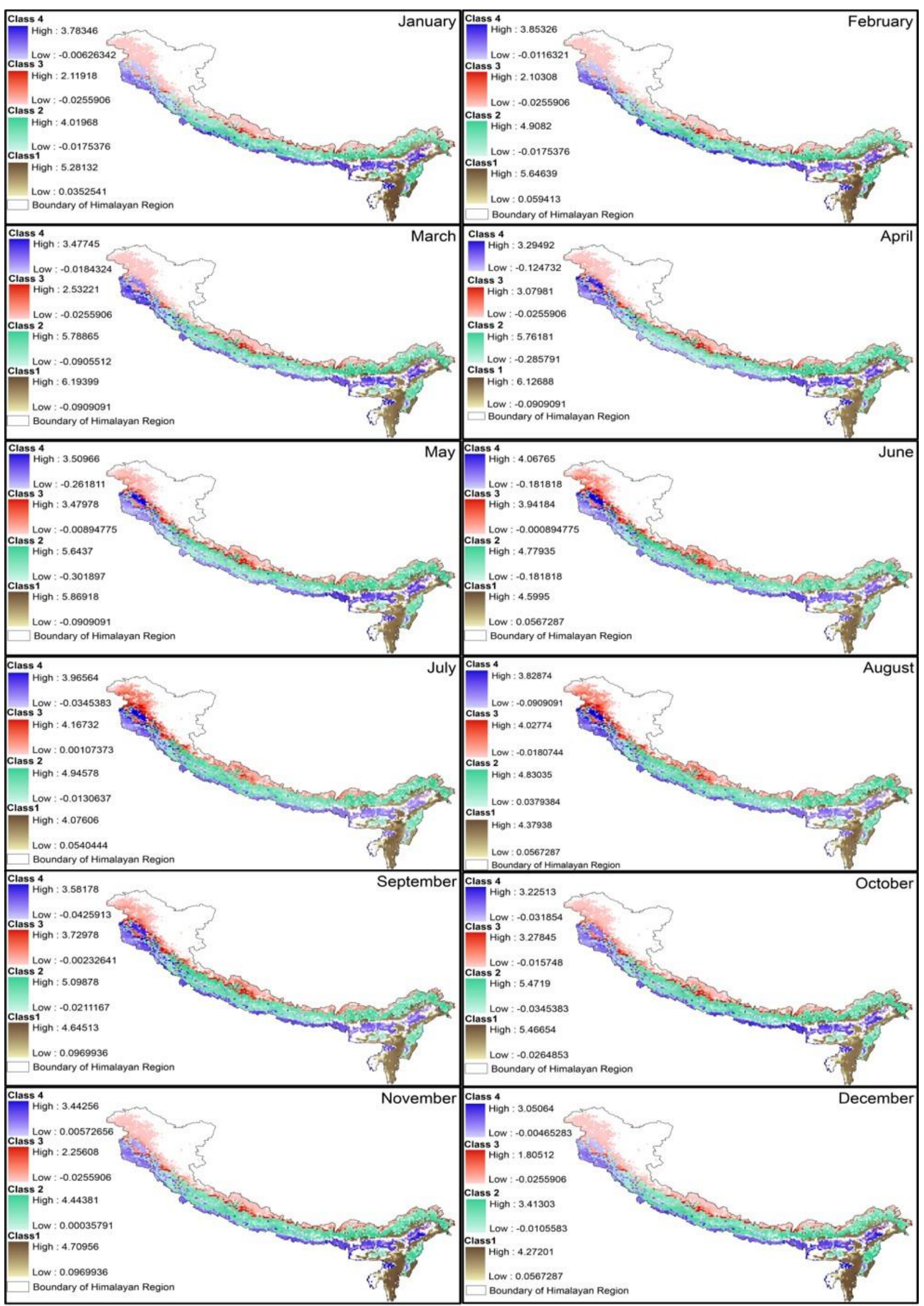

Figure 4. Spatial distribution of average month wise NPP values over the entire Himalayan region for four major classes. [Class 1- Evergreen broadleaf forest (EBL); Class 2- Mixed forest (MF); Class 3- Grass land (GL); Class 4- crop land (CL)] 


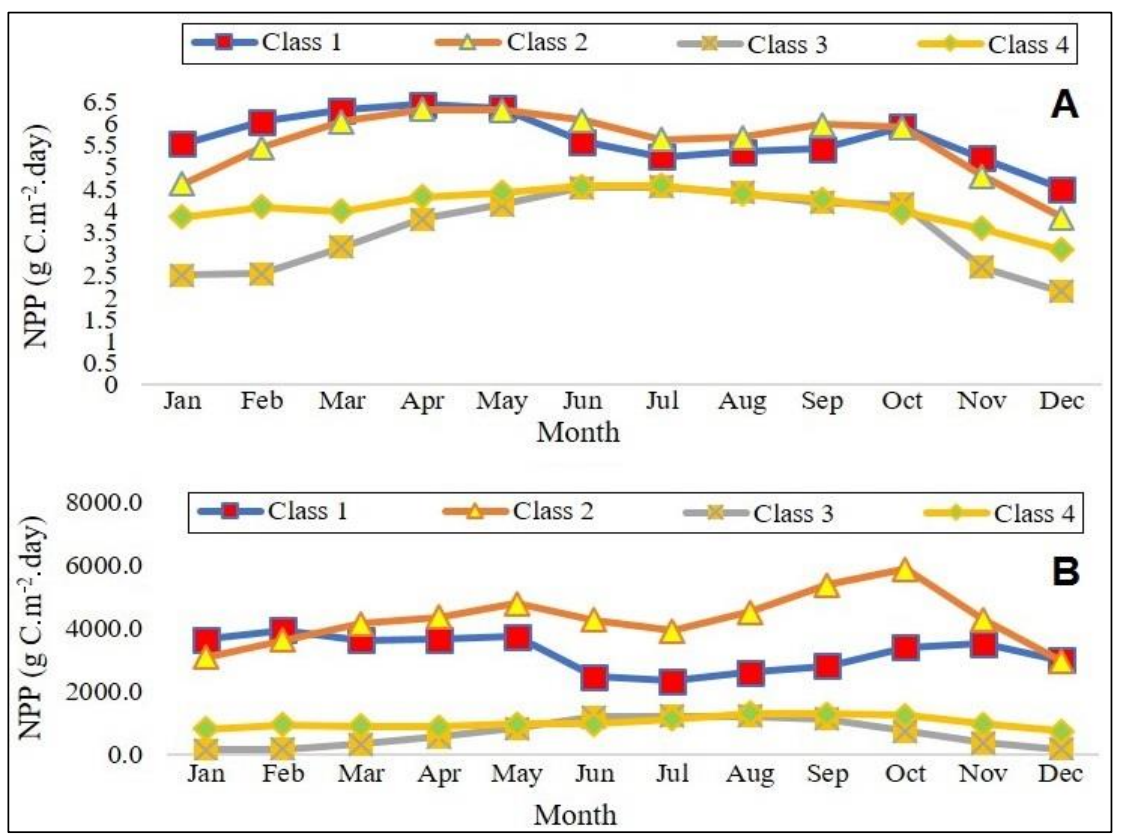

Figure 5. A, Month wise maximum NPP values observed over the entire Himalayan region; B, Month wise average of total NPP values for the entire Himalayan region for four major LCC. [Class 1- Evergreen broadleaf forest (EBL); Class 2- Mixed forest (MF); Class 3- Grass land (GL); Class 4- crop land (CL)]

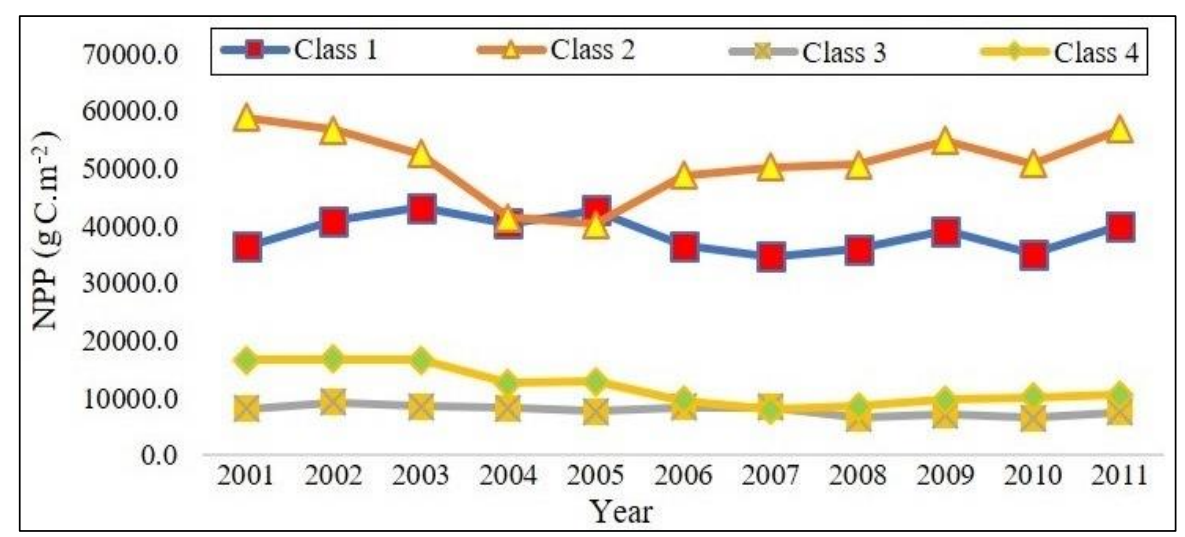

Figure 6. Year wise total NPP values for the entire Himalayan region for four major LCC. The year wise NPP values are obtained by adding NPP values from January to December. [Class 1- Evergreen broadleaf forest (EBL); Class 2- Mixed forest (MF); Class 3- Grass land (GL); Class 4- crop land (CL)]

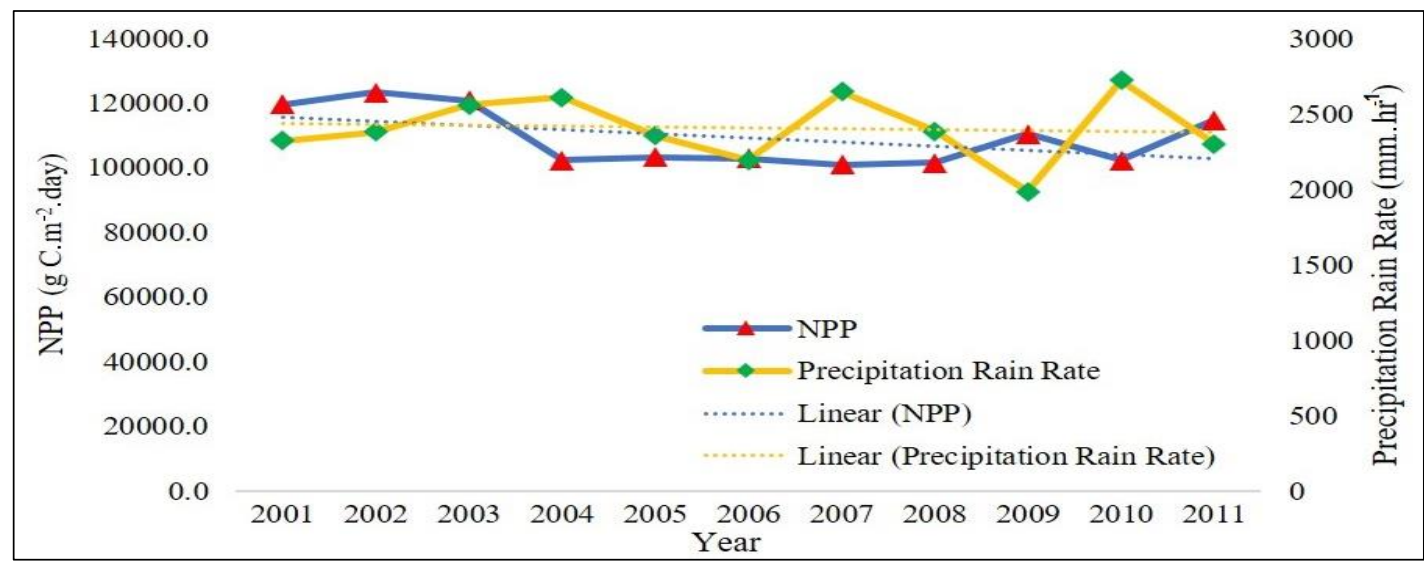

Figure 7. Trend between precipitation and annual total NPP.

\section{CONCLUSIONS}

This study is aimed at measuring the satellite-based NPP values to quantify the spatial and interannual variations over the IHR for a period of 2001-2011. Out of seventeen different land cover classes of the IHR, four dominant LCC were identified. It was observed that the land cover area and NPP of MF are maximum www.tropicalplantresearch.com 


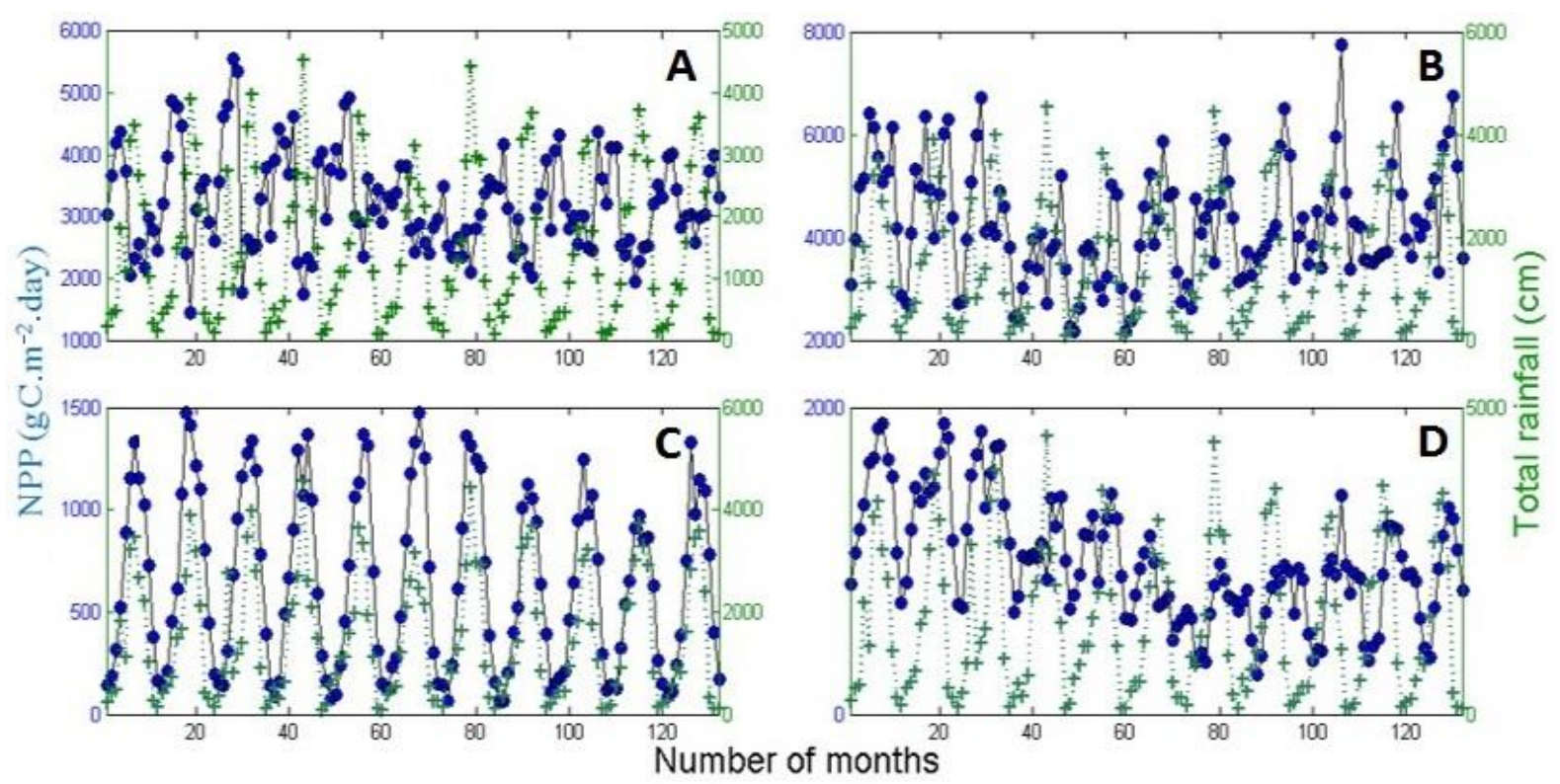

Figure 8. Significant curves between precipitation and NPP of four major LCC: A, Evergreen broadleaf forest (EBL); B, Mixed forest (MF); C, Grass land (GL); D, crop land (CL).

among all other LCC of IHR having an increasing trend for the period of 2001 to 2011. It was also observed that EBL is dominant in the North-eastern Himalaya having comparatively lesser spatial area than MF. The total annual NPP of EBL was also found to be decreasing. The total annual NPPs of GL and CL were also observed as decreasing the rates of 185.1 and $822.5{\mathrm{gC} . \mathrm{m}^{-2} \text {. day }}^{-1}$. The NPP products available from the website (www.neo.sci.gsfc.nasa.gov) were used for this study which had a spatial resolution of 0.1 Degree. No extra algorithm was used in this work to improve the regional scale estimate of NPP. Therefore, the NPP estimation presented in this work could be further improved if a finer resolution NPP and LCC product is used in the future. This work can further be extended in the context of climate change if long term climate and NPP products are available.

\section{ACKNOWLEDGEMENTS}

Authors are grateful to Director, GB Pant Institute of Himalayan Environment and Development (GBPIHED), Kosi-Katarmal, Almora, India for providing the necessary computational facilities and a research grant to carry out this work.

\section{REFERENCES}

Agrawal AK \& Goyal AK (1987) Effect on Grazing on Net Primary Production and System Transfer Function in a Western Himalayan Grassland Community. Tropical Grasslands 21(4): 154-158.

Bala G, Joshi J, Chaturvedi RK, Gangamani HV, Hashimoto H \& Nemani R (2013) Trends and Variability of AVHRR-Derived NPP in India. Remote Sensing 5: 810-829.

Bonan GB (2008) Forests and Climate Change: Forcings, Feedbacks, and the Climate Benefits of Forests. Science 320: 1444-1449.

Chakraborty K (2009) Vegetation change detection in Barak Basin. Current Science 96: 1236-1242.

Chhabra A \& Dadhwal VK (2004) Estimating terrestrial net primary productivity over India using satellite data. Current Science 86(2): 269-271.

Dhaulakhandi M, Rajwar GS, Kuniyal PC \& Kumar M (2010) Biomass and productivity of alpine pasture in Garhwal Himalaya, India. New York Science Journal 3(2): 40-44.

Farooq M \& Rashid H (2010) Spatio-temporal change analysis of forest density in Doodhganga Forest Range, Jammu \& Kashmir. International Journal of Geomatics and Geosciences 1(2): 132-140.

FSI (1999-2011) State of Forest Reports. Forest Survey of India.

Grosso DS, Parton W, Stohlgren T, Zheng D, Bachelet D, Prince S, Hibbard K \& Olson R (2008) Global potential net primary production predicted from vegetation class, precipitation and temperature. Ecology 89: $2117-2126$.

Gupta S, Singh S, Agarwal S \& Roy PS (2006) Degradation of Tropical Evergreen Forests in Mokokchung, Nagaland, India. International Journal of Ecology and Environmental Sciences 32(4): 345-356. 
Ives JD \& Messerli B (1990) The Himalayan Dilemma. United Nations University and Routledge, London and New York.

Joshi B \& Pant SC (2012) Monthly variation in plant biomass and net primary productivity of a mixed deciduous forest at foothills of Kumaun Himalaya. International Journal of Conservation Science 3(1): 41-50.

Jinguo Y, Zheng N \& Chenli W (2006) Vegetation NPP distribution based on MODIS data and CASA model A case study of Northern Heibei Province. Chinese Geographical Science 16(4): 334-341.

Kumar JIN, Sajish PR, Kumar RN \& Patel K (2011) Biomass and Net Primary Productivity in Three Different Aged Butea Forest Ecosystems in Western India, Rajasthan. Iranica Journal of Energy and Environment 2(1): 01-07.

Liu J, Chen JM, Cihlar J \& Park WM (1997) A process-based boreal ecosystem productivity simulator using remote sensing inputs. Remote Sensing of Environment 62: 58-175.

Liu J, Chen JM, Cihlar J \& Chen W (1999) Net primary productivity distribution in the BOREAS region from a process model using satellite and surface data. Journal of Geophysical Research 104 (D22): 27735-27754.

Melillo JM, Mcguire AD, Kicklighter DW, Moore B, Vorosmarty CJ \& Schloss AL (1993) Global climate change and terrestrial net primary production. Nature 363 (6426): 234-240.

Monteith JL (1972) Solar radiation and productivity in tropical ecosystems. Journal of Applied Ecology 9: 747766.

Monteith JL (1977) Climate and efficiency of crop production in Britain. Philosophical Transactions of the Royal Society of London, Ser. B: 277-294.

Palni LMS et al. (1998) Conservation of the Himalayan agro-ecosystem: issues and priorities. In: Eco regional Cooperation for Biodiversity Conservation in the Himalaya, United Nation Development Programme, New York, pp. 253-290.

Pandit MK, Sodhi NS, Koh LP, Bhaskar A \& Brook BW (2007) Unreported yet massive deforestation driving loss of endemic biodiversity in Indian Himalaya. Biodiversity and Conservation 16: 153-163.

Ramakrishnan PS (1988) Patterns of Primary Terrestrial and Ecosystems Function. Proceedings of the Indian National Science Academy. Part B 54 (5): 349-360.

Reddy CS, Dutta K \& Jha CS (2013) Analysing the gross and net deforestation rates in India. Current Science 105(11): 1492-1500.

Roy J, Saugier B \& Mooney HA (2001) Terrestrial Global Productivity. Academic Press, London, UK, 557 p.

Running SW, Nemani R, Glassy JM \& Thornton PE (1999) MODIS Daily Photosynthesis (PSN) and Annual Net Primary Productivity (NPP) Product (MOD17). Algorithm Theoretical Basis Document, 59.

Sharma E, Sharma R \& Pradhan M (1998) Ecology of Himalayan Alder (Alnus nepalensis D. Don). PINSA, B64 (1): $59-78$.

Shrestha UB, Gautam S \& Bawa KS (2012) Widespread Climate Change in the Himalayas and Associated Changes in Local Ecosystems. Plos One 7(5): 1-10.

Singh JS, Pandey U \& Tiwari AK (1984) Man and Forests: A Central Himalayan Case Study. Ambio 13: 80-87.

Singh RP, Rovshan S, Goroshi SK, Panigrahy S \& Parihar JS (2011) Spatial and Temporal Variability of Net Primary Productivity (NPP) over Terrestrial Biosphere of India Using NOAA-AVHRR Based GloPEM Model. Journal of the Indian Society of Remote Sensing 39: 345.

Soni S (2017) Evaluation of land-use land-cover change with changing climatic parameters of a watershed of Madhya Pradesh, India. Tropical Plant Research 4(1): 115-125

Strahler A (1999) MODIS Land Cover Product, Algorithm Theoretical Basis Document (ATBD), 66.

Tan K, Piao S, Peng C \& Fang J (2007) Satellite-based estimation ofbiomass carbon stocks for northeast China's forests between 1982 and 1999. Forest Ecology and Management 240(1): 114-121.

TRMM (2011) TRMM/TMPA 3B43 Tropical Rainfall Measuring Mission (TRMM) and Other Sources Monthly Rainfall Product V7, version 7, Green belt, MD: Goddard Space Flight Center Distributed Active Archive Center (GSFC DAAC), Accessed enter user data assess date as http://disc.sci.gsfc.nasagov/datacollection/ TRMM_3B43_V7.html

Zhang F, Ju W, Shen S, Wang S, Yu G \& Han S (2012) Variations of Terrestrial Net Primary Productivity in East Asia. Terrestrial Atmospheric and Oceanic Sciences 23(4): 425-437. 